\title{
A PROMISCUIDADE ENTRE TÉCNICA E CIÊNCIA EM JEAN-FRANÇOIS LYOTARD
}

\author{
The promiscuity between technique and science in Jean-François Lyotard
}

Mariana Ruiz Bertucci Schmitt

UFSC

Resumo: A finalidade do texto seguinte consiste na exposição de uma relação de promiscuidade entre a técnica e a ciência na obra de Jean-François Lyotard. A primeira etapa deste artigo consiste na apresentação de um problema referente à obra A condição pós-moderna (1979), onde a noção de técnica aparece sobre uma perspectiva positivista. Aqui, a intimidade entre técnica e ciência é resultado da crise dos fundamentos das ciências na modernidade, crise oriunda do afastamento entre as ciências e os discursos que se prestavam frequentemente à sua legitimação. Esses discursos, que Lyotard aproxima do modelo narrativo, e dos quais se destacam o discurso político de emancipação e o discurso filosófico especulativo, entram em declínio na condição pós-moderna. As ciências, desprovidas de motivações ou destinos humanistas, não resistem à lógica capitalista, e encontram o intermediário de sua relação com o capital na técnica. O critério da ciência deixa, pouco a pouco, de ser a busca pela verdade e passa a ser a busca pelo melhor desempenho. A segunda e conclusiva etapa do artigo, consiste, por sua vez, na radicalização dessa promiscuidade, e se refere principalmente ao livro $O$ inumano (1987). A assim chamada tecnociência corresponde à completa submissão da ciência à técnica: se a visão positivista de $A$ condição pós-moderna vê na técnica um suplemento, uma prótese que dá assistência à pesquisa científica, no segundo livro, a ciência se mostra a prótese ou o suplemento da técnica, que se revela, não obstante, inumana. Nessa segunda parte do artigo, pretendo mostrar que a visão positivista da técnica não é, portanto, suficiente para compreender a relação promíscua que ela tem com a ciência, mostrando-se necessário o recurso à perspectiva clássica da mesma: é a partir da visão da técnica como produtividade cega da physis que alcançamos também o entendimento do caráter inumano da tecnociência.

Palavras-chave: Técnica; ciência; legitimação; inumano.

Summary: The purpose of the following text is the exposition of a relationship of promiscuity between tecnique and science in the work of Jean-François Lyotard. The starting point of the debate is The postmodern condition (1979), where the idea of technique appears from a positivist perspective; in this text, the intimacy between technique and science is the result of a crisis of the foundations of science in modernity, arising from the distance between the sciences and the discourses that legitimized them. These discourses, that Lyotard approaches the narrative model, and wich he emphasizes the political discourse of emancipation and speculative philosophical discourse, begin to decline in the so-called postmodern condition. The sciences are devoid of humanistic motives or destinies, and can not resist the logic of capitalism. Thus the technique becomes the intermediary in the relationship between sciences and capital. The criterion of science ceases to be the search for truth and becomes the search for the best performance. The second and conclusive stage of the article consists, in turn, in the radicalization of this promiscuity, and refers mainly to the book The inhuman (1987). The so-called technoscience corresponds to the complete submission of the science to the technique: if the positivist view of The postmodern condition sees in the technique a supplement, a prosthesis that gives assitance to scientific research, in the second book is the science that shows up as the prosthesis or supplement of the technique, wich is, nevertheless, inhuman. In this second part of the article, I intend to show that the positivist view of technique is not therefore sufficient to understand the promiscuous relationship it has with science, and it is necessary to resort to the classical perspective of science: it is from the technique as blind productivity of physis that we also reach the understanding of the inhuman character of technoscience.

Keywords: Technique; Science; legitimation; inhuman. 


\section{Introdução}

O presente artigo tem por objetivo versar sobre uma relação promíscua entre a técnica e a ciência, que na obra de Jean-François Lyotard começa em A condição pósmoderna (1979) e se estende até $O$ inumano (1987), onde a relação é radicalizada e levada às últimas consequências. No primeiro texto, essa promiscuidade é fruto da seguinte conjectura: as ciências passam por uma crise na modernidade que se expressa na problematização tanto dos fundamentos das ciências, quanto das origens discursivas desses fundamentos, que amiúde se mostram extra-cientíticas, e uma grande consequência dessa crise é o divórcio entre o discurso científico e o discurso ético-político ou especulativo, estes que outrora lhe concediam legitimação. O estado das ciências diante dessa crise torna o seu campo do saber vulnerável à ação do capital, e esse estado de deslegitimação acaba abrindo espaço, finalmente, para um flerte fatal entre a ciência e a técnica.

Acompanha a crise das ciências o declínio daquilo que Lyotard chama os grandes relatos, ou as metanarrativas da modernidade, que são discursos teleológicos humanistas, discursos de emancipação e liberdade, mas também discursos especulativos, quer dizer, discursos totalizantes; a separação entre a ciência e esses discursos modernos de legitimação acontece no momento em que a emancipação do humano não é mais a força de promoção e distribuição do conhecimento científico, e tampouco o é o sistema totalizante que submete todos os discursos particulares sob a égide da especulação. Cada um à sua maneira, como será examinado adiante, esses dois grandes relatos, da emancipação e da especulação, representam e sugerem critérios de legitimação para as ciências, que passam a ser rejeitados quando nos deslocamos do ângulo de discurso moderno; destituída de legitimidade e à sua espera, a ciência parece recorrer ao critério técnico do melhor desempenho. É preciso anunciar de imediato que a noção de técnica, tal como ela aparece em $A$ condição pósmoderna, está vinculada a um ponto de vista positivista; em $O$ inumano, veremos que outras considerações sobre a técnica serão retomadas, como a sua compreensão clássica aliada à produtividade da physis, fortalecendo uma perspectiva mais escrupulosa sobre a mesma. 
Dessa forma, a partir de $A$ condição pós-moderna, dizer que a técnica se assume como critério para legitimação das ciências é assumir que a verificação (ou falsificação) de um enunciado será tanto mais legítima quanto melhor o seu desempenho, performance ou eficiência. Não se pode ignorar que esse encontro fortuito com a técnica é facilitado pela contaminação do capital nas ciências. Ademais, a ideia do desempenho como fio condutor da sobrevivência do sistema (à entropia) é central em todas as áreas do conhecimento que se apliquem à conveniência de uma teoria dos sistemas. A ideia de sistema gera discursos na física, nas ciências sociais, na economia, na política, na filosofia, na linguística, na cibernética, na telemática e em muitos outros paradigmas do saber. Essa perspectiva já está em Parsons, por exemplo, onde a metáfora da sociedade não se dá na forma de um organismo vivo, como em Durkheim, mas na forma de um sistema auto-regulável, quer dizer, cibernético simultaneamente otimista e tecnocrata, esse pensamento se fia sob a crença de um tipo de entropia capaz de estabilizar as economias em crescimento. Levando em conta este cenário de crise das ciências e declínio dos grandes discursos modernos, algumas perguntas urgem: por que as ciências precisam de um discurso extra-científico para Ihes validar? Porque as ciências passam a recorrer hegemonicamente ao critério técnico de legitimação do seu discurso na contemporaneidade, e quais as consequências dessa adesão? Como esse critério se impõe perante outros que poderiam disputar a autoridade pela legitimação científica?

Para responder essas questões e suscitar outras tantas, é preciso entender como a supracitada crise dos fundamentos da ciência conduz a um novo estatuto do saber que promove não só a sua fragmentação, mas também o abandono desses saberes então fragmentados em relação à adesão de motivações especulativas e/ou ético-políticas capazes de unificar e dar sentido à condução e avaliação de suas investigações, argumentações e resultados. Em consequência da constatação da falta de uma meta-regra aplicável a todos os jogos de linguagem, a ciência deriva para longe do cais da finalidade humanista de emancipação ou especulação que a ela se filiava nos discursos da modernidade. $O$ esclarecimento e o debate acerca dessas transformações na natureza da ciência quando da investida do critério técnico de legitimação sobre a mesma, deve-se sobretudo ao texto $A$ condição pós-moderna. 
Apesar da evolução do pensamento lyotardiano sobre a técnica se aproximar de uma visão quase "fáustica" sobre a mesma no livro de 1987, a sua concepção final de tecnociência desvela uma característica muito interessante que lhe é inerente: ela é como que inumana. Ora, isso quer dizer que a técnica se perfaz a despeito do empreendimento de uma finalidade antropomórfica e antropocêntrica, e que o próprio humano não passa de um veículo de sua empresa maior - a saber, dar continuidade à "mônada em expansão", à evolução técnica mesma, fazer-se sobreviver à entropia, ao determinismo cosmo local que se experimenta na Terra com a promessa da morte do Sol. Em O inumano, portanto, a falta de finalidade humanista da técnica mostra-se uma característica muito sedutora para a ciência (sedutora o suficiente para falarmos em tecnociência), que, divorciada do jogo ético-político e/ou especulativo veio também a se distanciar cada vez mais da guarda daquela finalidade humanista.

A promiscuidade entre a técnica e a ciência exposta em $A$ condição pósmoderna se radicaliza, portanto, em $O$ inumano: se no primeiro texto a técnica é vista sobretudo da perspectiva positivista, no segundo texto podemos perceber a interferência de uma noção clássica da mesma, e ela será vista, então, como algo cuja origem e o destino nos escapam, algo que se nos faz, mas que não é de nossa alçada, e sim da produtividade cega da própria physis. As duas considerações, positivista e clássica, acerca de técnica, não se excluem mutuamente no pensamento de Lyotard, apesar de constituírem um paradoxo eminente. A inumanidade da tecnociência é constituída, em última instância, a partir de certa compatibilidade entre as duas considerações; do ponto de vista positivista, a evolução técnica consiste na conquista da melhor performance, mas essa performance incrementada não pode ignorar o peso que o erro e o acidente lhe impõem de maneira imprevisível e mesmo inapreensível para nós, porque de modo geral não está no poder no humano manusear a sua produtividade, e sim no poder da physis, como queriam os gregos antigos, quer dizer, da natureza, que existe a despeito de nossas demandas. Essa radicalização da promiscuidade entre técnica e ciência se dá na própria inversão dos termos: na perspectiva positivista de $A$ condição pós-moderna, a ciência se utiliza da técnica, na perspectiva de inspiração clássica de $O$ inumano, a técnica se utiliza da ciência. Para tratar dos desdobramentos da promiscuidade entre ciência e técnica na obra de 
Lyotard, apresentarei, portanto, dois momentos deste fenômeno: I) como e porque a técnica, entendida como desempenho, eficiência ou performance se torna o critério hegemônico de legitimação das ciências na contemporaneidade, em $A$ condição pósmoderna (1979); e II) como a promiscuidade entre os termos se coaduna em um conceito de tecnociência que, resgatando uma noção clássica da técnica, concede-lhe um caráter inumano, no livro homônimo de 1987.

\section{I - Técnica e ciência em A condição pós-moderna}

Para entender o estatuto das ciências na condição dita pós-moderna - a condição cultural das sociedades pós-industriais, na metade do século XX -, Lyotard recorre, em primeiro lugar, à comparação entre os saberes narrativo e científico, a fim de mostrar, sobretudo, que as ciências sempre apelaram a critérios extrínsecos para sua legitimação. Se a legitimação não é exatamente um entrave para o discurso narrativo, ela é fundamental para a ciência, ao menos no Ocidente, e se expõe num problema ao mesmo tempo epistemológico e ético-político. Ora, claramente o saber não pode ser reduzido à ciência e nem sequer ao conhecimento: a lição de que o conhecimento é constituído de enunciados que descrevem objetos a fim de lhes declarar especificamente um caráter de verdade ou falsidade já está em Aristóteles. Nesse sentido, o saber excede o critério do conhecimento, e se estende a uma rede de critérios discursivos diferentes, possibilitando a formação de competências. O saber como formação e cultura associa critérios técnicos, critérios de justiça, beleza, felicidade, etc., expressando-se, portanto, numa globalidade que envolve o saberviver, o saber-ouvir e o saber-falar, enfim, numa pragmática que nutre o próprio vínculo social.

Para Lyotard, há uma preeminência do saber narrativo na fórmula do saber tradicional, na medida em que as histórias fixam os sucessos ou fracassos de um herói da comunidade, e esta fixação é o que legitima as instituições e a integração social, definindo critérios de competência e avaliando os desempenhos. A forma narrativa reúne, portanto, muitos jogos de linguagem e famílias de frases diferentes, com a finalidade de transmitir as regras da comunidade por meio da pragmática que é intrínseca aos seus relatos. Mais ainda: a forma narrativa estabelece um ritmo, que 
valoriza o metro, quer dizer, a cadência das ocorrências dos relatos, ante o acento, "a diferença de tom de cada performance ${ }^{1 "}$. Como a pragmática narrativa popular define, ao mesmo tempo, o que é permitido fazer e dizer em uma cultura, determina e avalia os critérios de competência por meio do uso de diversos jogos de linguagem, ela se legitima a si própria. Esse ponto marca uma incomensurabilidade entre a pragmática narrativa e a pragmática científica, porque esta última, reduzida agora ao título de um subconjunto do conhecimento, quer dizer, discurso que joga sobre o verdadeiro, por um método argumentativo, experimental e recursivo, isola o problema da legitimação e o transforma também em um referente.

Vejamos como funciona o jogo científico para Lyotard. Tomemos o exemplo do enunciado de Copérnico "a trajetória dos planetas é circular". Esse enunciado se pretende verdadeiro; a proposição gera algumas tensões, na medida em que cumpre ou não as prescrições que regulam o jogo científico, e dessas tensões se polarizam os postos pragmáticos (destinador, destinatário, referente). Para que o enunciado de Copérnico seja verdadeiro, ele precisa ser capaz de reunir provas daquilo que suspeita, e refutar os enunciados contraditórios acerca do mesmo referente. Cabe ao destinatário, que é um destinador em potencial, conceder ou recusar o consentimento sobre a verdade da proposição, e nesse sentido, se quiser refutar Copérnico, o destinatário precisará, por sua vez, reunir as provas para combate-lo segundo as mesmas prescrições que assombram os enunciados do cientista.

Ora, a comunidade científica reserva também a vez ao referente - este precisa expressar-se, em um enunciado cognitivo, como aquilo que ele é, de modo que acerca do referente "a trajetória dos planetas" se possa adequar sem escusas o predicado "é circular". O referente oferece, na ciência, matéria para argumento e prova, mas é por meio de duas prescrições, uma retórica e outra metafísica, que a própria prova pode ser concebida como verdadeira: retórica no sentido de que "quando eu posso provar, é permitido pensar que a realidade é como eu a digo"n, e metafísica no sentido de que o mesmo referente não pode oferecer provas contraditórias. Essas duas regras colocam um horizonte de consenso no jogo da ciência, que se expressa no processo de

\footnotetext{
1 LYOTARD, Jean-François. A condição pós-moderna. Rio de Janeiro: José Olympio, 2011, p. 41.

2 LYOTARD, Jean-François. A condição pós-moderna. Rio de Janeiro: José Olympio, 2011, p. 45.
} 
verificação no século XIX e de falsificação no século XX. Destinadores e destinatários constituem as trincheiras do jogo da ciência, e é preciso haver, não obstante, debate contraditório para elevar e avaliar os enunciados, conquistar e manter o interesse de um campo; o ensino e a didática asseguram a reprodução dos enunciados que são vítimas do consenso e, sedentarizados, tornam-se "verdades indiscutíveis", amplificando o alcance das ciências no vínculo social de modo geral, assim como a rede de formação de experts da competência específica de que se trata. Lyotard percebe uma tendência de supervalorização das provas nas ciências, o que vai ser precisamente o agente do seu vínculo com a técnica. O cientista passa a ocupar, assim, o lugar de profusão de enunciados verificáveis ou falsificáveis a respeito de um referente que pode ser acessado por um grupo de experts. É o consenso desses experts que deve conceder o caráter de "verdade científica" de um enunciado denotativo e ostentativo. Do mesmo jeito que o jogo científico privilegia o aspecto denotativo da linguagem, ele aparece como uma parte que compõe a sociedade indiretamente. Isto é, há uma exteriorização do saber científico, resultante da clivagem entre aqueles que podem participar de seu combate - os profissionais da ciência - e aqueles relegados aos outros saberes que ainda não são "secularizados". Essa exteriorização marca, ao mesmo tempo, "a queda do intelectual", e o caráter de anonimato do saber que então se desvela.

Diferentemente do discurso narrativo, a competência exclusiva do enunciador do sentido da frase, na ciência, suprime o equilíbrio entre o saber-falar, o saber-ouvir e saber-fazer. A supressão do saber-ouvir e do saber-fazer é um dos motivos pelo qual a ciência não encontra legitimidade nela mesma como a narrativa. No saber narrativo, é a pragmática de sua transmissão que lhe concede uma legitimação que não precisa de argumentos nem provas. Essa exigência de legitimação das ciências pode ser perigosa, porque ameaça os cientistas com o pensamento imperialista dos colonizadores, classificando o saber narrativo como selvagem, primitivo, atrasado, enfim, fábulas que entorpecem as mentes subalternas carentes da iluminação civilizatória. Mas o que se ignora aqui é que as ciências não estão absolutamente purificadas do discurso narrativo, e que a própria legitimação das ciências pode se dar por meio de uma função narrativa. É o que encontramos, segundo Lyotard, já no jogo do diálogo em 
Platão: na medida em que a forma dialógica (que seria a forma da discussão científica) do próprio diálogo é relatada, "o esforço de legitimação entrega as armas à narração ${ }^{3 \prime}$. Quer dizer: o saber científico, para atestar o verdadeiro saber, recorre, não obstante, ao relato, que é para ele " o não-saber". A sagacidade de Aristóteles estaria em ter separado as regras para os enunciados científicos (Organon) de um lado, e a investigação sobre a legitimidade desses enunciados no discurso sobre o Ser (Metafísica) de outro.

Na modernidade, esse problema da legitimação aparece sob a pergunta: quem decide sobre o que é verdadeiro? E o problema da legitimação mostra, enfim, porque ele é ao mesmo tempo epistemológico e ético-político, quando daquela primeira pergunta passa-se para a seguinte: "Qual é o sujeito cujas prescrições são as normas para aqueles que elas obrigam? ${ }^{4 \prime \prime}$. O entrosamento entre os jogos científico e éticopolítico se estreita no momento histórico em que o "povo", que é o herói da narrativa moderna de emancipação, atende aos mesmos operadores que o saber científico: "deliberação instituinte", "progressão cumulativa", "pretensão à universalidade", defende Lyotard ${ }^{5}$. Pela ambição de decidir sobre o verdadeiro e o justo, o "povo", herói da modernidade iluminista, assume a propriedade de um saber narrativo no seio das sociedades que, em vias de desenvolvimento industrial, experimentam pouco a pouco a erupção desses domínios discursivos.

É assim que a própria legitimação reintroduz o relato para validação do saber científico. Vejamos os exemplos privilegiados por Lyotard: um deles se faz numa versão política, que consiste na humanidade como sujeito histórico do relato prático, ou ainda, como herói da liberdade, e outro numa versão filosófica, que consiste no espírito como sujeito do relato cognitivo ou herói do conhecimento. Devemos reconhecer aqui a influência maioritária de Kant na primeira consideração e de Hegel na segunda. No relato prático, é patente que todo os povos têm direito à ciência, e que esse direito não pode ser ameaçado por nenhuma autoridade, seja pelos padres seja pelos tiranos. Este princípio orienta, sobretudo, uma política de ensinos primários, e é

\footnotetext{
3 LYOTARD, Jean-François. A condição pós-moderna. Rio de Janeiro: José Olympio, 2011, p. 55.

4 Idem.

5 Idem.
} 
aquele, por exemplo, da III República francesa; o Estado deve ser legitimado pelo povo, assumindo assim a função de formação, emancipação e garantia de liberdade do mesmo. Será legítima a pesquisa sobre a verdade se ela conduzir o homem à sua emancipação e liberdade, ou seja, se ela legitimar ao mesmo tempo o que se decide por justo.

Já no relato cognitivo, onde o herói é o sujeito do conhecimento ou o espírito especulativo, as ciências têm regras próprias, não têm finalidades determinadas, mas remetem também à formação espiritual da nação. Lyotard se pergunta como um efeito de Bildung pode resultar de uma pesquisa desinteressada do conhecimento; esse projeto é aquele da Universidade de Berlim, que serviu de influência para os cursos superiores nos séculos XIX e XX. Por recorrer indispensavelmente ao entrosamento entre o jogo científico o e o jogo ético-político, a Bildung do projeto humboldtiano promove a emergência do sujeito legítimo também pela síntese entre o verdadeiro e o justo; e por trair uma suspeita em relação ao Estado, o sujeito desse saber não é o povo, é o espírito especulativo. Nesse relato, diz Lyotard, o sujeito não pode encarnar, consequentemente, num Estado, como no caso da França pósrevolução, e sim num sistema. É assim que os projetos de totalização em Fichte, Schelling e Hegel conduzem à ideia de sistema, estrutura que restitui a unidade dos conhecimentos dispersos como devir do espírito.

Nota-se como o Estado precisa do saber especulativo para exprimir a verdade e a justiça do povo de modo legítimo. O saber especulativo encontra, portanto, legitimidade em si mesmo, ao modo de uma narrativa, e direciona a legitimidade ao Estado e à sociedade, servindo ainda de base para as ciências, e reafirmando o seu caráter meta-. Os enunciados são colocados em movimento no jogo especulativo, engendrando uns aos outros, sendo reiteradamente incorporados ao norte da especulação. É interessante notar que o marxismo oscila entre os dois relatos da modernidade: de um ponto de vista, o Partido assumiria o lugar da universidade, e as ciências não seriam mais que momentos do metarrelato do curso do socialismo (ou seja, a vida do espírito); de outro lado, o Partido poderia se desenvolver em saber crítico, e o socialismo apareceria como o sujeito autônomo que, por intermédio das 
ciências, fomenta os meios para a emancipação do sujeito prático empírico em relação ao capital ${ }^{6}$.

Ora, a partir dessa consideração dos discursos modernos que legitimam a ciência munidos de um álibi, no fim das contas, narrativo, podemos entender que o estatuto do saber se torna ainda mais turvo na condição dita pós-moderna em que esses relatos vêm ao declínio e o problema da legitimação se precipita em outros termos. Os relatos da emancipação e da especulação perdem a credibilidade; trata-se do "niilismo europeu" deflagrado por Nietzsche, incrementado pelos efeitos do desenvolvimento das técnicas e tecnologias desde a segunda guerra. A linguagem é fragmentada e a tarefa especulativa é constrangida ao regionalismo de um de seus confins. De outro lado, o discurso prático político não é menos afetado: o "povo" eleito como herói, alcança um nível de abstração tão intenso que não há identificação; as estratificações sociais e as promiscuidades entre os espaços sociais e simbólicos soterram-no. Além disso, o Estado tem maiores preocupações: o seu verdadeiro romance agora é com o capital. Isso leva Lyotard a cunhar esse processo como de uma deslegitimação. A transformação na natureza do saber que dá origem ao contexto intelectual reportado por Lyotard se faz perceber, portanto, também pela perda de seu "valor de uso" - o saber deixa de ter um fim em si mesmo, ele é então produzido para ser vendido e consumido, e representa, ainda, uma das principais forças de produção na competição mundial pelo poder (gera novos campos para estratégias industriais, políticas, militares, comerciais, etc.). De modo correlativo, a difusão dos saberes não mais se define pelo seu caráter formativo (Bildung) ou político, mas pela sua circulação nas redes da moeda e do mercado.

Diante dessas singelas considerações, o problema essencial que deve se destacar para entender a promiscuidade entre técnica e ciência é aquele da legitimação; este problema, como vimos, revela um entrosamento entre o discurso da ciência e aquele da ética-política que prevaleceu no Ocidente desde Platão até os discursos da modernidade. Esta questão é conhecida no debate da filosofia também como a questão fato-valor; ela mostra que para pensar o problema da legitimação da

${ }^{6}$ LYOTARD, Jean-François. A condição pós-moderna. Rio de Janeiro: José Olympio, 2011, p. 65. 
ciência ou do conhecimento sobre o verdadeiro, é preciso considerar também a legitimidade do legislador. Ora, em resposta à suspeita travada contra os grandes relatos da modernidade, Lyotard usa expressamente do método dos jogos de linguagem de Wittgenstein para expor sua análise sobre a supracitada conjuntura; os jogos de linguagem sugerem que a linguagem é fragmentada, que suas regras são locais, e que os "lances" (os enunciados) feitos num jogo provocam efeitos discursivos, esperados ou inesperados. As regras dos jogos de linguagem não se podem legitimar nelas mesmas, mas expressam sua soberania local através um contrato, explícito ou não, entre os jogadores. Todo enunciado é um "lance" em um jogo, e um "lance" capaz de transgredir a regra ou impor uma nova regra é imediatamente a criação de um novo jogo.

Para refletir sobre o problema fato-valor sob o ponto de vista dos jogos de linguagem, duas demandas se destacam. Em primeiro lugar, na leitura que Lyotard faz dos jogos de linguagem de Wittgenstein, a agonística é a saúde da linguagem, quer dizer, os combates que se enfrentam nos jogos é a maior riqueza de todo o jogar. A valorização do caráter agonístico da linguagem vai financiar a alternativa de legitimação para a ciência proposta por Lyotard: a paralogia ou o dissenso. Em segundo lugar, e ainda mais importante para o tema que se desenvolve aqui, se todo jogo é feito de regras (expressas ou não), então existem como que "meta-regras" ou "meta-prescrições", quer dizer, as sugestões ou ordens de condutas e procedimentos estão presentes em todo e qualquer tipo de jogo de linguagem, inclusive o jogo das ciências. Mas é preciso cuidado para entender bem essa ideia. Se por um lado a linguagem parece, em sua totalidade, contaminada pelo jogo ético-político, já que a definição de sua pragmática é a promoção de combates submetidos a ordens ou regras (e uma ordem ou uma regra é uma prescrição, ou seja, um enunciado ético, enquanto a adesão a uma ordem ou regra é um enunciado político), por outro lado é preciso lembrar que as ordens ou regras são sempre locais ${ }^{7}$, e não é legítimo que uma regra

\footnotetext{
${ }^{7}$ Ora, a localidade das regras dos jogos de linguagem evidencia as particularidades do caráter combativo ou agonístico dos jogos. Assim, temos por exemplo: o jogo da ciência é a disputa entre os enunciados do conhecimento do verdadeiro, através de recursos proposicionais lógicos, argumentativos e experimentais. Não se avalia um enunciado científico pela sua beleza, ou pela sua justiça, ou pela sua fé, e sim pela sua veracidade - ou falsificação. Já o enunciado estético, por sua vez, será avaliado pela sua pertinência no debate dos sentimentos do belo e do sublime, assim como da filosofia da arte, e reivindicará recursos filosóficos, argumentativos e artísticos, dentre outros. Esses recursos presentes em ambos os dois jogos, da ciência e da estética, usados como exemplo ilustrativo, podem ser entendidos aqui como as famílias de frase de Wittgenstein. As famílias de frase são
} 
local possa assumir o posto de uma "meta-prescrição" propriamente dita, dedicada a abarcar ou fundamentar todos os jogos de linguagem - como acontece com o tipo de discurso especulativo, que reitera os jogos particulares às suas próprias demandas, consideradas ainda universais.

A questão é, então, a seguinte: o lugar de uma "meta-prescrição" na linguagem precisa estar sempre desocupado, malgrado o fato de que todos os jogos são constituídos de regras, o que significa, finalmente, que o conteúdo discursivo éticopolítico tampouco tem legitimidade para assumir-se como "meta-prescrição" da linguagem - não se pode estabelecer de uma vez por todas e para todos os jogos que o debate acerca do que é certo fazer e seguir seja o parâmetro geral de pertinência da linguagem. A destituição do critério ético-político para a legitimação da ciência é componente de um contexto mais largo e mais profundo de irradiação do domínio do capital, e da cumplicidade que ele trama com a técnica. Ademais, não é exagero anunciar que a fragmentação da linguagem em jogos com regras locais é, sob essa perspectiva, o pesadelo do discurso especulativo. Ao mesmo tempo que começa o thriller entre a técnica e a ciência, sob a direção do capital, salta-nos à vista, do outro lado, o lugar que devem ocupar o discurso ético e político. Dando a este último a função de "guardião da linguagem", Lyotard aproxima os jogos de linguagem do arquipélago crítico kantiano: em que consiste a crítica senão na vigília dos limites entre os territórios da Razão, do entendimento, da sensibilidade, etc., e na conclusão de que nenhum deles pode reivindicar a coroa?

Feitas as ressalvas a respeito do paradoxo da "meta-prescrição" dos jogos de linguagem, essa é a diretriz da sua leitura do problema da legitimação no conhecimento científico, tal como ele se expressa tradicionalmente no Ocidente, problema que passa, portanto, como aquele do fato-valor, do qual conclui-se com Lyotard que não há implicação lógica em predicar o verdadeiro (aquilo que se procura versar em ciência) do justo (aquilo que se procura versar em ética e/ou política), ou vice-versa. Bem vimos que todo o processo descrito acima fundamenta a motivação de Lyotard para resolver este problema do fato-valor; mas agora que as ciências não mais

diferentes regimes enunciativos, como o argumentativo, prescritivo, interrogativo, ostentativo, que são dinamizados de acordo com as demandas dos jogos de linguagem. 
recorrem ao princípio de emancipação da humanidade nem tampouco à totalização do conhecimento que realiza o destino do espírito especulativo, é preciso entender, finalmente, como a técnica passa a reger a tarefa de legitimação das ciências.

Lyotard afirma que a pesquisa científica consiste, atualmente, em duas demandas fundamentais: o chamado enriquecimento das argumentações e a complicação da administração das $\operatorname{provas}^{8}$. Chamo a atenção do leitor à observação de que essas duas demandas são as matrizes de dois modos de legitimação das ciências; quer dizer, na medida em que a complicação da administração das provas dirige o norte das ciências para o critério do desempenho empregado pela técnica, o enriquecimento das argumentações aparece como a principal demanda do critério de legitimação por paralogia ou dissenso. O uso do critério técnico de desempenho ou performance se expande com força e rapidez porque ele é hegemonicamente eleito entre as teorias do sistema, como foi dito, e se adapta, portanto, com fluidez à lógica do sistema capitalista.

O desafio que diz respeito à questão da argumentação das provas e que é valorizado, sobretudo, pelo modo técnico de legitimação das ciências, consiste em fazer aceitar um novo enunciado a partir do testemunho de uma prova material, e o próprio referente (a realidade) é convocado e debatido por meio desse recurso na comunidade científica. O ponto de vista descrito tem como partida a limitação dos nossos sentidos e o engodo a que são constantemente ameaçados; assim, as técnicas empregadas na administração das provas substituem os órgãos ou sistemas fisiológicos com a finalidade de prover constatações livres das arbitrariedades e obsolescências dos nossos sentidos. Tendo em mente que o princípio das técnicas, na perspectiva positivista, é a otimização das performances, quer dizer, o aumento de output (informações ou mudanças conquistadas) e a diminuição do input (energia gasta), um "lance" técnico será considerado um "bom lance" se for bem-sucedido gastando o mínimo de energia. Essa é uma definição tardia da competência técnica, alerta Lyotard: dentre os gregos antigos, a técnica estava ligada não só ao conhecimento, mas também às artes e à toda produtividade da physis. Na contemporaneidade, esse

8 LYOTARD, Jean-François. A condição pós-moderna. Rio de Janeiro: José Olympio, 2011, p. 77. 
aspecto fundamental da técnica, que é, em outras palavras, seu acontecimento episódico, inapreensível mesmo, e casual, no sentido de acaso, não se revela como o traço triunfante de sua natureza, mas sim a sua atuação incisiva na administração da prova científica, conquanto ela seja também a mediação entre a ciência e o capital. Promove-se uma equação entre riqueza/eficiência/verdade, o que nos leva a desconfiar que "os mais ricos têm mais chances de ter razão"." Como já havia sugerido Lyotard, nas sociedades de capitalismo desenvolvido, não há riqueza sem técnica.

A intimidade entre técnica e lucro é mais orgânica que aquela entre a técnica e a ciência, afirma Lyotard. É o capital que resolve o problema do crédito para pesquisas científicas, seja na iniciativa privada, seja na iniciativa pública, por meio de universidades, programas, empresas, etc. A lógica das universidades não é menos empresarial que qualquer outro empreendimento institucional, seu distanciamento da motivação e destinação especulativa ou emancipatória não podia ser mais marcante. A administração da prova deixa de ser, ademais, uma etapa ou uma demanda da argumentação que se destina à busca de consentimento da comunidade científica, porque ela passa então a ser controlada pelo jogo da técnica, onde o que está em questão não é, sobriamente, a verdade, mas o desempenho, a melhor performance input/output; nem o Estado, nem a universidade, nem a empresa se apegam ao antigo critério de legitimação idealista ou humanista para justificar o combate no jogo científico. A legitimação é como uma batata quente no livro de Lyotard: ela passa de um jogo ao outro, de um critério ao outro, não firma estabilidade em nenhum lugar por muito tempo. Se um jogo não é um destino, se mudar de regra é mudar de jogo, o debate do problema da legitimação parece trazer justamente o desconforto do abandono dos preceitos humanistas e totalizantes que davam organicidade e sentido à interação dos jogos em uma metanarrativa, ou seja, nos discursos modernos de emancipação ou especulação.

De qualquer modo, o critério de desempenho somado à administração das provas aumenta as chances de se "ter razão", o que quer dizer que o critério de eficiência tem, de fato, efeito sobre o critério de verdade, e a promiscuidade entre

9 LYOTARD, Jean-François. A condição pós-moderna. Rio de Janeiro: José Olympio, 2011, p. 81. 
técnica e ciência começa a se tornar cada vez mais evidente. Como as técnicas são vistas como "aparelhos que otimizam as performances do corpo humano" ${ }^{10 "}$ incrementando o "poder discriminador" dos sentidos, seu crescente domínio sobre a ciência e até mesmo sobre a ética-política vem de um consequente processo de "assenhoramento" da realidade, quer dizer, a realidade enquanto referente se torna um recurso incansável de fornecimento de provas para argumentação científica, cujos resultados devem interferir nas prescrições de ordem jurídica, política e ética.

Lyotard nota que em relação ao ensino, as disciplinas relacionadas a cibernética e telemática tendem a crescer e se tornar prioritárias, de modo que a formação das competências especializadas, que atendem às exigências de performance do sistema social, possa alargar a comunidade dos experts, por meio de uma função profissionalizante e técnica, que pouco ou nada tem a ver com o ideal humanista ou emancipatório das universidades e dos estudantes quando de sua versão democrática. Uma consequência desse processo é que o critério performático ou de desempenho deve acabar por subordinar as instituições de ensino superior aos poderes instituídos. Suprime-se, assim, o questionamento sobre o verdadeiro, hegemonicamente, pelo questionamento sobre o eficaz, o rentável, e cria-se uma rede mercadológica de competências operacionais: "a enciclopédia de amanhã são os bancos de dados. Eles excedem a capacidade de cada usuário. Eles são a 'natureza' para o homem pósmoderno ${ }^{11 "}$. Lyotard se refere constantemente em $O$ inumano à condição da "falta" de natureza de que dispomos na contemporaneidade; essa escassez se refere ao simétrico excesso da disposição cumulativa da memorização de dados e da respectiva operacionalidade das informações, assim como da exploração perene sobre o referente, ou seja, a realidade.

No dito saber pós-moderno, diz Lyotard, o discurso é imanente às regras que o legitimam - e isso explicitamente. Essa mudança na natureza do saber provoca a discussão sobre o entrosamento entre a performance e as teorias dos sistemas, presentes, como foi sugerido, em diversas ciências. Ora, Lyotard, instalando-se na perspectiva dos jogos de linguagem, pretende se manter diametralmente distante da

\footnotetext{
10 LYOTARD, Jean-François. A condição pós-moderna. Rio de Janeiro: José Olympio, 2011, p. 80.

11 LYOTARD, Jean-François. A condição pós-moderna. Rio de Janeiro: José Olympio, 2011, p. 93.
} 
perspectiva dos sistemas, sobretudo pela força que o desempenho técnico exerce nesta última. O interesse pela física e cosmologia é um atenuante das discussões de Lyotard sobre o assunto; usando a física clássica como exemplo de uma teoria do sistema na ciência, o autor quer mostrar como a ideia da termodinâmica, ou seja, a relação entre trabalho e gasto de energia, expressa também na lei da entropia, é associada à "representação de uma evolução previsível das performances do sistema". O único preceito é que se conheçam todas as variáveis do sistema para controlar o seu contexto. A proposição de Laplace fornece um enunciado desse tipo: se estiver à minha disposição todas as variáveis que determinam o estado do universo no tempo $t$, tenho então a previsão do resultado do tempo $t^{\prime}>t$. Esse enunciado se fia no princípio de que os sistemas físicos transparecem suas regularidades, têm uma trajetória previsível.

Com o princípio da incerteza na física quântica, esse bastião é abalado: em primeiro lugar, a física quântica declara que é impossível descrever o estado inicial de um sistema, isto é, determinar todas as suas variáveis, ao menos com nosso domínio técnico, e que, ademais, a despesa para concebê-lo, se fosse possível, seria no mínimo equivalente àquela consumida pelo sistema que espera a nossa definição. O que equivale a dizer que: a ideia de que um controle absoluto de um sistema seria suficiente para incrementar suas performances é paradoxal, e, assim, inconsistente: na busca de economizar energia, quer dizer, na busca do melhor desempenho, gastar-seia toda a energia. Notem como essa inconsistência aparece transplantada para o campo socioeconômico: na obsessão do controle do contexto, as burocracias estatais sufocam os subsistemas que compõem o sistema social. Nem sequer se pode conceber algo como definir precisamente o "estado inicial" de um sistema social sem incorrer em gravíssimos problemas.

No entanto, o que é muito interessante, é que enquanto possibilidade de princípio, aquele pensamento como o de Laplace, ou seja, de uma trajetória previsível para os sistemas físicos, ainda continua firme, constitui ainda um paradigma acessado frequentemente em física. Como se sabe, o determinismo clássico sobrevive amiúde a despeito das novas regras impostas pela física quântica. Entropia e princípio de regularidade ainda constituem prioritariamente o limite concebível dos sistemas 
físicos. A teoria quântica impõe uma revisão das premissas assumidas pelo determinismo clássico; o seu problema não é tanto o da falta de desenvolvimento técnico suficiente para provar seu ponto. O problema da incerteza é, antes, a constatação de que a precisão do exame não é capaz de garantir o aumento de controle do contexto. Prevalece um jogo de informação "incompleta", diz Lyotard, entre o que "fala a natureza" e o enunciado do cientista: "No nível microfísico, uma "melhor" informação, isto é, com maior capacidade de desempenho, não pode ser obtida. A questão não é a de conhecer o que é o adversário (a natureza), mas saber o jogo que ela joga ${ }^{12 ”}$. Um deslocamento entra a física clássica e a física quântica está na "redução" do nível de determinismo, que se torna meramente probabilista na última. Outro exemplo de Lyotard é aquele de René Thom, que interroga, por sua vez, a noção de um sistema estável, tal como pressuposto naquelas duas versões da física, ainda que de maneira mitigada na teoria quântica. Fala-se aqui em "ilhas de determinismo"; o conflito, "pai de todas as coisas", desde Heráclito, impõe à teoria das catástrofes um determinismo local. É assim que essas pesquisas inspiram Lyotard à alternativa da paralogia ante a técnica para legitimação das ciências. Bem, Lyotard não acredita na legitimação pelo consenso; por essa via, ou repetimos o grande relato da emancipação, como quer Habermas, e suprimimos a condição de localidade das regras e valores dos jogos, ou corremos o risco da manipulação do sistema acerca do consenso. Para Lyotard, a finalidade do diálogo não é o consenso, e sim a paralogia, quer dizer, a erupção de novos e inesperados enunciados: o consenso é apenas um estado da discussão. De modo geral, o consenso é algo local e revogável. Não se pode pedir a todos os locutores da linguagem que entrem em acordo acerca das "metaprescrições" que seriam como que válidas para todos os jogos - isso é absurdo na pragmática da linguagem proposta por Lyotard, tal como retomada de Wittgenstein.

A legitimação por dissenso ou paralogia é aquela que valoriza sobretudo a invenção imaginativa do cientista. Ela atesta, como diz Medawar ${ }^{13}$, que o maior êxito do cientista é, simplesmente, ter ideias, e por isso trata-se, majoritariamente, de uma demanda de enriquecimento das argumentações. Ora, a própria pragmática do saber

\footnotetext{
12 LYOTARD, Jean-François. A condição pós-moderna. Rio de Janeiro: José Olympio, 2011, p. 104.

13 LYOTARD, Jean-François. A condição pós-moderna. Rio de Janeiro: José Olympio, 2011, p. 108.
} 
científico é o dissentimento, afirma Lyotard; se o consenso se estabelece como horizonte de estabilização de um paradigma, o dissenso ou paralogia é um poder de desestabilização das capacidades explicativas, que tem como consequência a circunscrição de novos campos de pesquisa. Sua implicação é simetricamente oposta àquela da eficiência do sistema que reina na legitimação pela técnica: trata-se da condição de imprevisibilidade das descobertas. Ela "relega o consenso para mais tarde ${ }^{14 \prime \prime}$, e mostra a pouca pertinência da legitimação prevista pela teoria dos sistemas, a técnica do ponto de vista positivista, que não dá conta nem da ciência nem da sociedade. Lyotard não nega, por fim, que há "vantagens" no critério positivista de desempenho; ele não abre mão do seu arsenal argumentativo, mesmo em $O$ inumano. Mas é preciso pensar se o fato de não aderirmos mais em ciência aos pressupostos metafísicos e humanistas é suficientemente satisfatório e, além disso, se a identificação do social com uma totalidade em fuga perene do determinismo, responde consistentemente às demandas paradoxais do vínculo social - não é favorecendo os desfavorecidos que o desempenho otimiza o sistema. A paralogia, por outro lado, desmantela a estrutura do poder: é fácil recusar o consenso mínimo em relação a um "lance" muito "forte", porque ele altera as condições de estabilidade que regem o consenso já sedentarizado dentro de um campo - pensem no "lance" que dá origem à teoria das cordas, na física, e na dificuldade que e esse "lance" sofreu, quanto tempo levou para ser finalmente admitido pelos destinatários com algum consenso (o seu impacto era, nada mais, nada menos que uma conciliação, mesmo que mitigada, entre a física clássica e a quântica).

Na paralogia, a pertinência ou o critério de um enunciado está na sua capacidade de gerar novas ideias, ou seja, em promover a agonística das ciências. Ela não pretende disfarçar a falta de uma meta-regra que fundamente todas as ciências e todas as demandas de cada ciência, ao contrário, ela acentua essa ausência e, assim fazendo-o, proíbe a identificação da ciência com o sistema. Lyotard acrescenta que a clivagem entre os decisores (ou seja, investidores capitalistas) e executores (quer dizer, os cientistas) diz respeito ao sistema socioeconômico, e não à pragmática científica, e

${ }^{14}$ LYOTARD, Jean-François. A condição pós-moderna. Rio de janeiro: José Olympio, 2011, p. 113. 
mostra-se, ademais, como um dos maiores obstáculos da imaginação, da inventividade do pensamento científico. Além de tudo isso, a paralogia na pragmática científica tem como norte a investigação das regras que tornam os enunciados científicos admissíveis - mais que isto: oferece aos parceiros de jogo outros enunciados que se podem tornar regras. Por mais desolador (ou satisfatório, depende do seu ponto de vista) que possa parecer, é de se imaginar que, nesta leitura da pragmática social, as diversas classes de enunciados heteromorfos que seguem diferentes regras de admissão nos jogos específicos não encontram, salvo acaso, compatibilidade com os enunciados científicos. Essa compatibilidade fica relegada ao discurso moderno, e só deve ser admitida como sofrimento e perda para um discurso que não tenha passado pela rotação de ângulo que se impõe aos discursos quando do declínio dos grandes relatos da modernidade. A ideologia do sistema é o que se presta a esta ânsia totalizante.

\section{II - Tecnociência em O inumano: uma inspiração clássica}

Ao nos referirmos à tecnociência apresentada nas páginas de $O$ inumano, precisamos entender que ela é um modo de acolhimento do acontecimento ontológico, que em Lyotard é, por princípio, indeterminável. A atividade tecnocientífica, tal como ela é conduzida pelo humano, exigiria, portanto, a revisão de seu estatuto àquele de uma autoria compartilhada com uma passividade anônima, a que venho chamando de inumano. No livro que leva o mesmo nome, o inumano é um "hóspede desconhecido" que habita o próprio humano, e que interfere, de modo desinteressado, nas mais diversas atividades que costumamos associar à ação ou decisão humanas, como a ética, as ciência, as artes, a filosofia, etc. Convém associar o inumano a uma passividade porque ele é frequentemente expresso na figura de algo que é determinante, tanto no âmbito dos sintomas individuais, quanto no âmbito dos gêneros de discurso e das instituições, mas que permanece, todavia, indeterminado. Lyotard sugere, com o inumano, uma ideia de ontologia na qual o Ser não se nos destina; nessa ideia, na verdade, o Ser se dilui em acontecimentos, e o sujeito humano é marginalizado, eleito pelo acaso e movido inexoravelmente numa rede de encadeamentos de acontecimentos os quais ele tem pouco ou nenhum controle. 
Com o conceito, mesmo que furtivo, de matéria, Lyotard reinstitui, por outro lado, no mesmo livro, uma metafísica de cunho cosmológico em sua filosofia: ao modo da physis, a matéria seria uma produtividade cega de seus fins, mutante e desinteressada, cuja centrífuga opõe os encontros e os desencontros dos humanos com as artes e as tecnociências. O sujeito humano, não obstante, é híbrido, quer dizer, ele é passivo-ativo, ele também se dispersa em regimes de frases e gêneros discursivos incomensuráveis; a própria concepção do humano em Lyotard é paradoxal, e repousa na ambiguidade entre uma indeterminação nativa e um vir a ser da razão (ou melhor: das razões). Ademais, as produções das artes e das tecnociências evidenciam enfaticamente, aos olhos do autor, a necessidade do reconhecimento daquela autoria compartilhada com este desconhecido que se chamou o inumano. $\mathrm{O}$ acontecimento ontológico será, para Lyotard, esse terreno de indeterminação que antecede e torna possível as razões, não só em $O$ inumano, mas também em textos como Economia libidinal (1974) e $O$ diferendo $(1983)^{15}$. Há deslocamentos entre as obras, mudança de léxico, revisão de problemáticas, mas em todos os casos, apesar do acontecimento ontológico ser por princípio indeterminável, a necessidade ${ }^{16}$ dos encadeamentos dos acontecimentos possibilita e mesmo fomenta que diversos jogos ou gêneros de discurso venham a versar sobre o seu "referente", e suscitam, assim, modos de acolhimento do acontecimento ontológico também diversos. Trata-se do levante ôntico, ou ainda, do vir a ser das razões. Em O inumano, Lyotard fala de dois modos de acolhimento, o do sublime e o da tecnociência. Eles são opostos: o sublime se lança, por meio das artes, ao desapossamento que a indeterminação nativa é capaz de promover no sujeito, submetendo-o a um "estado de espírito sem espírito"17"; a tecnociência, por sua vez, presume-se possuidora da determinação do acontecimento - ou ao menos, possuidora dos meios de diminuir cada vez mais a sua indeterminação.

\footnotetext{
15 Em todas essas obras, as razões, a consciência, o próprio sujeito, aparecem como possibilidade, mas não como finalidade: no livro de 1974, eles são frutos do acaso das determinações do desejo, que é, por definição uma força incompossível e imprevisível de movimento e investimento, e no livro de 1983, é a linguagem que ocupa o lugar deste indeterminado que nos determina. As reflexões sobre o inumano declaram, na letra de Lyotard, a urgência da revisão dos preconceitos antropomórficos e antropocêntricos.

${ }^{16}$ Essa necessidade não é da ordem de uma heteronomia ética ("tu deves"), nem tampouco na ordem dos conhecimentos científicos, mas antes da certeza, no sentido wittgensteiniano, ou ainda, na opção kantiana frente às antinomias da razão pura, que diz que a série dos acontecimentos deve poder ser infinita porque recusar este mesmo argumento é dar continuidade à série. Se houver algo como o "último acontecimento", a supressão da série, não haverá um encadeamento sobre ele capaz de expressar que aquele fora o último.

${ }^{17}$ LYOTARD, Jean-François. O inumano - considerações sobre o tempo. Lisboa: Editorial Estampa, 1900. P.144
} 
Levar em conta uma ontologia do inumano seria, portanto, reconhecer, nas conquistas tecnocientíficas, uma autoria mitigada com o indeterminado, com o desconhecido, e revogar a teleologia humanista da ontologia, assim como o narcisismo embutido na concepção positivista vulgar da técnica.

O leitor ou a leitora deve se lembrar que a técnica foi descrita, em $A$ condição pós-moderna, como prótese da ciência. Isso porque os sentidos humanos são limitados em extensão, e precisam de suplementos justamente para ultrapassar essas limitações, no conhecimento e sua aplicabilidade. É esse aspecto, sobretudo, que confirma o seu caráter positivista, associado à sua descrição como desempenho ou performance previsível em um sistema - ou seja, o caráter positivista da técnica fortalece, no mais das vezes, a instituição de uma visão humanista da técnica como instrumento usado pelo humano para fins científicos. Em $O$ inumano, a então chamada tecnociência vai marcar a radicalização da promiscuidade entre os dois termos que agora formaram esse novo conceito; aqui, a ciência está totalmente submetida à técnica, e o que precisa ser elucidado é que se trata de uma rotação de perspectiva que, promovendo a inversão das relações entre uma e outra, desautoriza ainda mais, por assim dizer, os discursos humanistas que colocam nas mãos do homem o domínio da técnica.

Retomemos a inversão de que falávamos: a técnica não é mais vista como a prótese do humano e da ciência, o humano e a ciência são vistos como próteses da técnica. Ora, o que Lyotard quer dizer com a ideia de que a ciência humana é uma prótese da técnica? Apesar do impacto talvez retórico da proposição, o que Lyotard quer evidenciar é, sobretudo, a necessidade de compartilhar uma perspectiva sobre as tecnociências e as artes que não seja mais aquela da produção tética de um sujeito transparente, enaltecendo que o paradoxo e a dispersão do sujeito interditam uma concepção estável suficiente do humano e problematizam, portanto, todos os discursos que o tomam como algo dado. Bem, se considerarmos a tecnociência uma atividade de autoria compartilhada entre o humano, ou a ciência humana, e o inumano, aquela produtividade cega da matéria, podemos sugerir que o domínio e o alcance da tecnociência não estão completamente à disposição do controle humano. Nesse sentido, a ciência humana será entendida como a prótese da técnica em uma 
empreitada cósmica de sobrevivência (da própria técnica) à entropia, ou ao determinismo cosmo-local que se experimenta agora aqui na Terra. Concordo que até aí a inversão entre técnica e ciência mais não faz que uma saturação ampliada do pensamento guardado pelo positivismo. Mas não é só isso. A contribuição da influência clássica, que interdita, em certa medida, a conclusão humanista e narcisista que habita o positivismo, está em que nada garante o privilégio do humano em relação à técnica. Além de instituir uma certa heteronomia entre o sujeito e algo desconhecido que se Ihe perfaz na atividade tecnocientífica, se a ciência humana é prótese da técnica, é porque o humano tem pouco ou nenhum privilégio no controle dessa atividade tida como compartilhada. Precisamente porque o humano é, enquanto prótese, o suplemento de sua complexificação, o seu veículo ou continuador: mas não o portador destinado por todo o cosmo ao domínio do melhor desempenho. Apesar da visão positivista estar impregnada na ideia de entropia associada ao determinismo cosmo-local, e implicar, assim, no mínimo, a ideia de sistema físico, é notadamente encorajada a argumentação de que o humano, ser obviamente de sofisticado desenvolvimento técnico, é fruto do acaso das efervescências, improváveis, imprevisíveis e ininvestigáveis da produtividade técnica da matéria - que substitui, com deslocamentos, a ideia da physis, e concede-lhe o caráter de inumanidade. Diz Lyotard: "Sabem, a técnica não é uma invenção dos homens. Talvez o contrário" Essa inversão parece sofisticar a noção de técnica em Lyotard, porque agora ela não é simplesmente um recurso que está sempre à disposição da ciência ou do cientista: ela tem a sua própria "agenda". O que é o mesmo que dizer: A técnica não é só manipulação de desempenho enquanto resistência à entropia em um dado sistema, ela é também, e paradoxalmente, produção imprevisível, versão a mais inumana do conflito e do acaso.

Compreender o processo de deslegitimação da ciência, tal como fizemos na parte anterior, é valioso ao presente texto na medida em que consiste precisamente na substituição do critério humanista/metafísico pelo critério técnico, que caracteriza, então, a dita condição pós-moderna das ciências: quando as metanarrativas entram

18 LYOTARD, Jean-François. O inumano - considerações sobre o tempo. Lisboa: Editorial Estampa, 1990, p. 20. 
em colapso, as ciências passam por uma crise porque perdem elas mesmas o seu fundamento e o seu critério de legitimação. Alinhando-se ao princípio técnico de legitimação, a ciência passa a ser julgada simplesmente pelo seu desempenho melhor performance possível entre o input e o output - e terá a garantia de sua performance fortalecida pela sua aliança com o capital, que tem o mesmo interesse sistêmico de desenvolvimento e que tem o poder de fornecer todo custeamento para a produção de provas e experiências. O capitalismo é um sistema tão particular que parece que a técnica lhe convém tanto pelo seu aspecto positivista quanto pelo seu aspecto inumano. Esse cenário da condição cultural pós-moderna, cuja descrição se intensifica em $O$ inumano, nos impõe uma condição existencial totalmente pautada no cálculo, o que seria a própria armação ou gestell heideggeriano.

O noivado entre a ciência e a técnica, que tem como testemunhas as universidades e o capital como padrinho, torna-se o catalisador do crescimento econômico nos países capitalistas desenvolvidos, devido à relação de reciprocidade que se estabelece entre poder, ciência, direito e técnica; literalmente donos da "realidade", eles criam uma rede de dependência entre as ordens jurídica, política, ética e científica na qual o poder e a eficiência extrapolam a incomensurabilidade de princípio entre os jogos de linguagem. Contudo, essa aparência de poderio da humanidade sobre a técnica, donde despontam a exploração inconsequente da natureza e dos desafortunados pelo sistema, não deve nos impedir de olhar ainda mais além, se estivermos dispostos a ver aquilo que Lyotard defende ser o verdadeiro caráter, tanto do capitalismo quanto da tecnociência - a sua inumanidade, a sua contribuição, casual e não cognoscível para um processo de complexificação (neguentropia) indomável, dentre cujos efeitos estão mesmo a riqueza e o lucro.

É assim que a tecnociência lyotardiana se aproxima da pesquisa de Heidegger sobre a técnica, especialmente daquilo que o último chama armação: esta seria como um princípio de interpelação, como o é a poiesis, uma chamada da existência ${ }^{19}$, diz Heidegger, de um saber que ocorre através da atividade humana, mas cujo sentido,

\footnotetext{
19 Creio que a ideia da interpelação pela técnica enquanto chamada da existência seja um ponto de distanciamento entre Heidegger e Lyotard: a ideia de chamada ou chamamento em Heidegger expressa ainda, aos olhos de Lyotard, uma compreensão antropocêntrica e antropomórfica da interpelação ontológica, como se nos destinássemos ao chamado do Ser.
} 
assim como na antiguidade, projeta algo além do humano e fora do seu controle seria talvez o mesmo que dizer: a técnica se nos faz, desinteressadamente. A instauração do paradigma matemático como princípio difusor de toda ciência e visão de mundo, assim como a espúria pretensão moderna de que o pensamento deve ser fundamentado unicamente em proposições cognitivas e científicas, o crescente predomínio do pensar enquanto ratio, tudo isto encobre o fato de que a própria técnica moderna não é técnica em si mesma, quer dizer, remete antes e sempre a proposições não cognitivas, ou se preferir, poiéticas: "A energia atômica é objeto de um cálculo e de um controle efetuado por uma tecnologia que chamamos física nuclear, mas o fato de essa última obrigar a natureza a agir desse modo é - sem prejulgar todo o restante - um fato metafísico ${ }^{20 "}$.

A essência da técnica na modernidade é claramente distinta da essência da técnica na antiguidade: antes vista como um saber oriundo da physis e conjugado com a atividade humana, a técnica, que do humano não provinha como origem e nem a ele se dirigia como destino último, passa por um longo processo, que vai, grosso modo, desde a substituição da noção de verdade como aletheia para veritas, à crescente matematização das ciências, com Galileu e adiante, maravilhosamente descrita na Crise das ciências europeias de Husserl, chegando mesmo à impregnação de uma visão de mundo científica que se impõe sobre uma base de enunciados cognitivos recalcando aqueles que não o são; ora, todo esse processo encarna, na condição da técnica na contemporaneidade, finalmente, na percepção do humano como meio ou veículo da técnica, e não como finalidade. Esse engodo ou essa ingenuidade em relação ao domínio do homem sobre a técnica é uma perspectiva que deixa entrever o caráter inumano daquilo que chamamos tecnociência. Este caráter inumano da técnica parece recoberto na modernidade, dada a contaminação do antropocentrismo e do antropomorfismo dos discursos filosóficos e científicos, que instigaram a compreensão do humano como destino final da técnica, esta não passando, então, de um saber - positivista - expresso pelo cálculo e fundamentado no princípio de abstração completa dos quanta - a physis nada mais do que seu manancial de recursos

\footnotetext{
${ }^{20}$ RÜDIGER, Francisco. Martin Heidegger e a questão da técnica-prospectos acerca do futuro do homem. Porto Alegre: Sulinas,
} 2006, p. 120. 
-, capaz de promover a dominação daquilo que, outrora, se nos oferecia como mistério. Não dirigida pelo humano, a tecnociência contemporânea descrita por Lyotard deve contribuir, contudo, para uma revisão do seu narcisismo: abandonado o suporte humanístico que legitimava a ciência, o humano pode ser considerado não "como origem nem como resultado, mas como um transformador que assegura, pela sua tecnociência, as suas artes, o seu desenvolvimento econômico, as suas culturas e a nova memorização respectivas, um suplemento de complexidade no universo ${ }^{21 "}$. Ou seja: uma prótese.

O próprio humano, em sua ambiguidade, aparece aqui como acaso das determinações da matéria, não detém o monopólio do espírito, é simplesmente um "transformador", um contribuinte deveras ingênuo de sua condição, improvável e passageiro (eis a graça!). Seria preciso entender, nesse sentido, que o verdadeiro utilizador da linguagem não é o espírito humano enquanto humano, diz Lyotard, mas enquanto complexidade em movimento, cujo espírito não passa de um suporte transitório ${ }^{22}$. Ora, se o motor da tecnociência não está sob controle do humano, se este último é tão improvável quanto passageiro, isto que damos continuidade, quer dizer, a complexificação inelutável, por meio da tecnociência, deve nos levar - e nos está levando - àquilo que se poderá nos substituir, digamos assim, quando, limitados ao corpo e à morte, não pudermos mais perseverar a tarefa designada. É disso que se valem a cibernética e a inteligência artificial, dentre outras, e é nesse sentido que a ciência, enquanto tecnociência, é uma atividade paradoxal que divide a autoria entre o humano e o inumano. A cultura dita pós-moderna promove, pouco a pouco, a substituição do dispositivo técnico de organização do tempo e do espaço, que era próprio das etnoculturas. As narrativas míticas são demasiado tributárias do contexto histórico e geográfico no qual operam, profundamente telúricas; por sua vez, as novas tecnologias que promovem a cultura pós-moderna, num processo de incrementar constante de sua própria desenvoltura, operam dispositivos técnicos desenvolvidos

\footnotetext{
${ }^{21}$ LYOTARD, Jean-François. O inumano - considerações sobre o tempo. Lisboa: Editorial Estampa, 1990, p. 54.

22 LYOTARD, Jean-François. O inumano - considerações sobre o tempo. Lisboa: Editorial Estampa, 1990, p. 79.
} 
para o desdém com o corpo, desvelando seu alcance cósmico. Enquanto "mônada 23 em expansão", o humano contribui mais para o processo de complexificação cosmolocal de que fala Lyotard do que para qualquer progresso na emancipação do humano em termos de formação, de liberdade ou de política, revelando que apesar da vaidade antropocêntrica que lhe faz crer no seu domínio sobre a técnica, é antes a técnica que confere ao humano o status de vetor e continuador daquele indeterminado que é determinante: a matéria, o inumano.

Apesar da técnica não ser propriamente da alçada do humano, o seu caráter positivista permanece vívido, como já foi sugerido. Do mesmo jeito que a física clássica não deixa de "ter sentido" quando aplicada aos grandes objetos, a despeito de suas inconsistências com a física quântica, que também não deixa de "ter sentido" quando aplicada aos objetos muito pequenos, a técnica, do ponto de vista positivista é continuamente encorajada pelas ciências e pelos cientistas, mesmo que o seu caráter inumano exija, por sua vez, uma revisão do seu humanismo. Essa revisão que não chega sempre a ser gerida nesse campo do saber - o que pode ser feito, tal como em Lyotard, recorrendo à uma inspiração clássica da técnica como produtividade cega da physis, ou da matéria. Destarte, a tecnociência não pode deixar de ser vista, tal como em Heidegger, como um acolhimento do acontecimento ontológico, assim como a própria poiética: esta última ele atribui a origem aos Gregos, e a primeira, ele atribui a origem ao pensamento leibniziano, que, pelo princípio da razão suficiente, engendra funcionalmente com a empreitada da tecnociência, sobretudo em seu aspecto positivista.

O pensamento de Lyotard estaria muito mais de acordo com a ontologia poética; apesar das críticas dirigidas a Heidegger, desde o antropocentrismo de sua fenomenologia, até a escolha do povo Grego como epicentro da ontologia poética, o seu viés se abre para uma compreensão da linguagem como campo de alteridade e contingência do acontecimento, e é notadamente aí que se encontra a resistência de Lyotard à acolhida tecnocientífica. Ora, o princípio de razão suficiente não respeita essa alteridade e contingência próprios do acontecimento ontológico: ele supõe, ao

\footnotetext{
${ }^{23}$ Entendendo por mônada aqui um sistema técnico, operatório e eficaz de armazenamento, retenção e distribuição de informações.
} 
contrário, que todo acontecimento deve ser explicado como efeito de uma causa a ser determinada pela razão. Novamente, está na presunção laplaciana, está na física clássica. No acolhimento pela poiética de Heidegger, e no acolhimento pelo sublime de Lyotard, a linguagem seria pensada como campo de percepção "capaz de fazer sentido por si próprio, independentemente de qualquer intenção de significar ${ }^{24 \prime \prime}$. A própria atitude de pensar consiste em aceitar a ocorrência como não dada, tanto na linguagem habitual, quanto na poética ou mesmo na linguagem racional, é preciso "estar apto para receber o que o pensamento não está preparado para pensar ${ }^{25}$ ". Essa ideia final de Lyotard não deixa de rimar com aquela alternativa de legitimação pela paralogia ou dissenso.

\section{Conclusão}

Lyotard começa a perceber uma relação promíscua entre a técnica e a ciência em $A$ condição pós-moderna. Vista como otimização do desempenho, a técnica aparece nesse texto como recurso utilizado pela ciência e pelos cientistas, para promover experiências capazes de lhes render provas pertinentes para a instituição dos enunciados a que se prestam, assim como ampliar a condição de previsibilidade do sistema com a finalidade de aumentar seu controle sobre o mesmo. Essa visão positivista da técnica revela, por um lado, uma vaidade humanista, que consiste na aceitação - talvez ingênua, quer dizer: inquestionada - de que o cientista e a sua ciência dominam a técnica. Ela é para a ciência e para o cientista uma prótese ou suplemento. Ora, vimos também que o contexto cultural, histórico e epistemológico desse encontro entre técnica e ciência é aquele do declínio dos discursos - relatos - da emancipação e da especulação. Esse declínio já demonstra a dificuldade de legitimar a ciência por meio de um critério humanista. Mas o que acontece com a transição para a tecnociência em $O$ inumano é que se mostra necessário abrir mão do humanismo de modo ainda mais radical: é preciso rever o humanismo que habita a própria noção de tecnociência, destituindo o domínio da técnica do controle do humano - ou seja,

\footnotetext{
24 LYOTARD, Jean-François. O inumano - considerações sobre o tempo. Lisboa: Editorial Estampa, 1990, p. 78.

${ }^{25}$ LYOTARD, Jean-François. O inumano - considerações sobre o tempo. Lisboa: Editorial Estampa, 1990, p. 80.
} 
invertendo a equação de modo que a ciência e os cientistas aparecem como próteses ou suplementos do movimento de complexificação técnica.

Sofisticando a noção de técnica enquanto produtividade cega da physis, ou do seu equivalente em Lyotard, a matéria, e acrescentando-Ihe o caráter de imprevisibilidade, o autor consegue mitigar o determinismo, que poderia permanecer do ponto de vista positivista, mesmo quando este for capaz de eliminar o narcisismo humanista. Se compararmos as noções de técnica tal como elas aparecem em $A$ condição pós-moderna e $O$ inumano, só podemos chegar a uma compreensão paradoxal da mesma: o caráter positivista da técnica, que a pressupõe como prótese doada ao auxílio dos sentidos humanos e recurso de acesso à previsibilidade do sistema rivaliza, precisamente, com o caráter de surpresa e imprevisibilidade que a noção de inspiração clássica supõe, e que serve de base para a inversão daquela primeira proposição. Esse paradoxo vai resultar na ideia de uma autoria compartilhada na produção tecnocientífica, entre a atividade humana e a passividade indeterminável inumana. Mas não se enganem: nessa autoria compartilhada, o humano ou a ciência não detém o domínio seguro da técnica, nem o seu destino, e o próprio inumano, por sua vez, nos é desinteressado, sua finalidade, se há, é-nos desconhecida. Por fim, se a tecnociência assim conjugada aparece em O inumano com certa conotação "fáustica", como foi sugerido na introdução, é justamente na medida em que as duas perspectivas sobre a técnica são convenientes ao capital, e que na autoria dividida entre o humano e o inumano, que se testemunha na tecnociência, a grande esmagadora maioria da humanidade, assim como os recursos naturais da Terra e do espaço circundante, encontram-se ameaçados pela força dominante do capital, em sua respectiva e evidente inumanidade. Se Lyotard concede tanto privilégio àquilo que chama o inumano, essa passividade anônima, é porque, no entendimento do autor, a revisão narcisista do humanismo tecnocientífico urge. Os preconceitos antropológicos precisam ser revistos, e o questionamento sobre a ambiguidade do humano não pode ser abandonado. Atentando à inumanidade da tecnociência, podemos perceber com mais nitidez o modo como as suas conquistas estão distantes das demandas éticas, políticas e mesmo ecológicas; mas, por outro lado, evidenciar o seu caráter positivista 
também não nos aproxima da problematização ética, política ou ecológica, talvez, antes, aproxime-nos da vaidade antropocêntrica que o anima.

\section{Referências bibliográficas}

LYOTARD, Jean-François. Economie libidinale. Paris: Les éditions de minuit, 1974. . Le différend. Paris: Les éditions de minuit, 1983.

. A condição pós-moderna. Rio de Janeiro: José Olympio, 2011. . O inumano - considerações sobre o tempo. Lisboa: Editorial Estampa, 1990.

RÜDIGER, Francisco. Martin Heidegger e a questão da técnica - prospectos acerca do futuro do homem. Porto Alegre: Sulinas, 2006.

WITTGENSTEIN, Ludwig. Investigações filosóficas. São Paulo: Editora Nova Cultural, 1999. 